\title{
Facile Synthesis of Porous SnSb Alloy Anode for Li-Ion Battery
}

\author{
Wei Fan, Chunling Qin*, Weimin Zhao, Bo Liao* \\ School of Materials Science and Engineering, Hebei University of Technology, Tianjin, China \\ Email: *clqin@hebut.edu.cn, *laorll@aliyun.com
}

How to cite this paper: Fan, W., Qin, C.L., Zhao, W.M. and Liao, B. (2019) Facile Synthesis of Porous SnSb Alloy Anode for Li-Ion Battery. Materials Sciences and Applications, 10, 1-11.

https://doi.org/10.4236/msa.2019.101001

Received: November 29, 2018

Accepted: December 26, 2018

Published: December 29, 2018

Copyright (c) 2019 by author(s) and Scientific Research Publishing Inc. This work is licensed under the Creative Commons Attribution International License (CC BY 4.0).

http://creativecommons.org/licenses/by/4.0/

\section{cc) (i) Open Access}

\begin{abstract}
$\mathrm{Sn} / \mathrm{Sb}$ based alloy anodes have attracted considerable interest as electrodes for next-generation high performance Li-ion batteries (LIBs) owing to their high theoretical capacities. And fabricate porous structure is an effective way to improve materials' cycling performance. Here, we developed nanoporous SnSb alloy ribbon (NP-SnSb) through a melt-spinning/chemical-etching process and took it as electrode of LIB directly. Being of self-supported and binder free, the NP-SnSb shows a total outperformance over its nonporous counterparts both in cycling performance and kinetic characteristic. Besides, considering the melt-spinning/chemical-etching synthetic process is high-throughput and simple, the ribbon kind of alloy anodes have strong potential application for LIBs research.
\end{abstract}

\section{Keywords}

Lithium-Ion Batteries, Porous Structure, SnSb Alloy Electrodes, Melt-Spinning, Dealloying

\section{Introduction}

Due to their high Li-storage capacities, alloy-based anodes such as $\mathrm{Si}, \mathrm{Ge}, \mathrm{Sn}$ and $\mathrm{Sb}$ have been received intense attention since the 1980s for lithium rechargeable batteries [1] [2] [3] [4] [5]. To be specific, the theoretic specific capacity of $\mathrm{Sn}$ and $\mathrm{Sb}$ are $994 \mathrm{mAh} \mathrm{g}^{-1}\left(\mathrm{Li}_{4.4} \mathrm{Sn}\right)$ and $660 \mathrm{mAh} \mathrm{g}^{-1}\left(\mathrm{Li}_{3} \mathrm{Sb}\right)$ respectively. For comparison, it is as much 2.7 times and 1.8 times as that of graphite $(372 \mathrm{mAh}$ $\mathrm{g}^{-1}$ ) [6] [7] [8]. However, a serious problem for alloy materials is the rapid pulverization during lithiation/delithiation cycles [9] [10] [11]. So, superfine alloy, active/inactive and active/active composite alloy materials, such as $\mathrm{Sn} / \mathrm{SnSb}$, $\mathrm{Sn} / \mathrm{SnCu}$, and $\mathrm{SnSb} / \mathrm{C}$ have been made to improve structural stability of materials [12]-[17]. As for active/inactive and active/active composite materials, the 
active component can form in situ and disperse uniformly within the inactive matrix at the atomic or nanometer scale [18] [19] [20], thus the volume variation of the active component could be alleviated and the cyclic performance of alloy anodes improve impressively. Given the melt-spinning is a scalable, high-yield and rapid solidification process with high quench rates of $\sim 10^{6} \mathrm{~K} \cdot \mathrm{s}^{-1}$, which can impart the alloys with nanocrystalline/amorphous features and intriguing material traits [21] [22], we here intend to use the method to produce the SnSb alloy ribbons of active/active composite and investigate its electrochemical performance in lithium-ion batteries.

During the entire Li-ion diffusion route, the solid-state diffusion of $\mathrm{Li}$ in host materials is the rate determining step which influences the power density of the battery. The diffusion rate is in inverse ratio to the diffusion length square [23]. From the traditional microscale electrode materials to the nanometer particles, a reduction length from several $\mu \mathrm{m}$ to about $50 \mathrm{~nm}$, the diffusion rate can increase by more than three orders of magnitude. So, nanosized materials have significant advantages in kinetics. However, it was found that when the particle size of active material is less than $100 \mathrm{~nm}$, the particles would aggregate and merge into micrometer-scale particles during repeat $\mathrm{Li}$ insertion and extraction, thus lose the kinetic advantage [24] [25]. Although the aggregation can be alleviate by mixing dispersant such as carbon black with the active material, the introduction of the electrochemically inactive dispersant or matrix will cause the capacity loss of the electrode. Given the benefits endowed by porous structure, such as high tolerance toward the volume expansion [26], shortening Li-ion diffusion distance and facilitating the permeating of electrolyte into the electrodes, especially the high conductivity and excellent electrochemical/mechanical stability that nanoporus metals (NPMs) present [27], it is the porous architectures that should be feasible to increase the cycling performance of SnSb alloy anode. As is known, dealloying is a general corrosion procedure in which the "pores" is fabricated by selectively removal of more chemically active element from parent alloy within acidic or alkaline aqueous environment [28] [29]. Being low-cost and facile to scale production as the melt-spinning, chemical dealloying is an ideal method to fabricating porous structure.

As mentioned above, many approaches have been undertaken to mitigate the issues of poor cycling stability of bare SnSb anode. However, most of these strategies seem to be inappropriate for practical applications owing to their poor-scalability and throughput. Our approach is to develop a high-performance anode for LIBs through a commercial process which could further find its potential in novel cell configurations. Herein, we prepared SnSb alloy ribbons (P-SnSb) with different molar ratio and then fabricated nanoporous $\mathrm{SnSb}$ alloy (NP-SnSb) ribbons by selective removal of $\mathrm{Sn}$ in $\mathrm{NaOH}$ aqueous solution. Both electrochemical performances of $\mathrm{P}-\mathrm{SnSb}$ and NP-SnSb for LIBs have been investigated by taking the alloy ribbons as anode. Especially, detailed voltammetric analysis was used to investigate the electrochemical kinetic characteristic of both kinds of anode. Attention was 
also paid to the morphology variation of the alloy ribbons.

\section{Material and Methods}

\subsection{Synthesis of $\mathrm{SnSb}$ Alloy Ribbons}

Firstly, $\mathrm{Sn}_{80} \mathrm{Sb}_{20}$ (at\%), $\mathrm{Sn}_{50} \mathrm{Sb}_{50}$ (at\%) and $\mathrm{Sn}_{20} \mathrm{Sb}_{80}$ (at\%) alloy ingots were prepared by melting pure $\mathrm{Sn}\left(\geq 99 \%\right.$ purity) and $\mathrm{Sb}\left(\geq 99 \%\right.$ purity ) at $1500^{\circ} \mathrm{C}$ in an arc melting furnace under argon flow. The prepared high-purity ingots were then transferred to a holding quartz tube and fixed in the single-roller meltspinner with a $20 \mathrm{~cm}$ diameter $\mathrm{Cu}$ wheel in an argon filled chamber. The distance between the bottom of the quartz tube nozzle and the surface of the copper wheel was $50 \mathrm{~mm}$, and the rolling rate of the wheel was $50 \mathrm{~Hz}$. The ingots were induction melted to molten liquid and then pressure ejected through the slotted nozzle. Upon contact with the water-cooled copper roller with rotation speed of $2500 \mathrm{r} / \mathrm{min}$, the molten liquid rapidly solidified into very thin flakes with the thickness $\sim 1 \mathrm{~mm}$.

\subsection{Synthesis of Nanoporous SnSb Alloy Ribbon}

The ribbon precursors were chemical dealloyed in $2 \mathrm{wt} \% \mathrm{NaOH}$ aqueous solution at $30^{\circ} \mathrm{C}$ for $6-72$ hours. During the dealloying process, Sn atoms were selectively dissolved into alkaline solution, while the $\mathrm{Sb}$ atoms remained. The outcomes were washed times with ultra-pure water $(18.2 \mathrm{M} \Omega \cdot \mathrm{cm})$ until the $\mathrm{pH}$ was 7 and then dried in a vacuum oven at $60^{\circ} \mathrm{C}$ for $12 \mathrm{~h}$ before further treating.

\subsection{Material Characterization}

The phase composition was verified by an X-ray diffractometer (XRD, Bruker, D8-Advance) using $\mathrm{Cu} \mathrm{Ka}$ radiation at a step rate of $5^{\circ} \mathrm{min}^{-1}$. The morphology of the samples was observed under a scanning electron microscope (SEM, FEI, Verios 460L) equipped with an X-ray energy dispersive spectroscope (EDS).

\subsection{Electrochemical Measurements}

To measure the electrochemical performance, the 2032 coin cells were assembled using the $\mathrm{P}-\mathrm{SnSb} / \mathrm{NP}-\mathrm{SnSb}$ as the working electrode, the $\mathrm{Li}$ foil as the counter electrode, a Celgard 2400 as the separator, and 1 M LiPF6 in ethylenecarbonate/dimethyl carbonate $(\mathrm{EC} / \mathrm{DMC}=1: 1$, volume ratio) as the electrolyte. To standardize the measurement, a fixed amount (about $100 \mu \mathrm{L}$ ) of electrolyte was used in each coin battery. All the cells were installed in a glovebox with water and oxygen content lower than $1 \mathrm{ppm}$ and measured at room temperature. The electrochemical tests were measured in a CR2032 type coin cell. A lithium foil was used as the counter electrode. The working electrode was fabricated by two methods. The first one was to use alloy ribbons directly as anode. The mass of the ribbons was typically $\sim 7 \mathrm{mg} \mathrm{cm}^{-2}$ with the dimension of $10 \times 2 \times 1 \mathrm{~mm}$.

Galvanostatic discharge/charge tests were performed on the battery testing system (LAND CT2001A, China) at room temperature. The cyclic voltammetry 
(CV) test was carried out on an electrochemical workstation (Princeton Applied Research, PARSTAT 2273) from 0.1 to $2.5 \mathrm{~V}$. The electrochemical impedance spectroscopy (EIS) measurements were carried out on an electrochemical workstation (Princeton Applied Research, PARSTAT 2273) with the frequency ranged from $0.01 \mathrm{~Hz}$ to $100 \mathrm{kHz}$ and an amplitude voltage of $5 \mathrm{mV}$.

\section{Results and Discussions}

\subsection{Microstructural and Phase Characterizations of $\mathrm{P}-\mathrm{SnSb}$}

The melt-spun SnSb alloy ribbons with Sn:Sb molar ratio of 80:20, 50:50 and 20:80 were characterized by X-ray diffraction (XRD). As shown in Figure 1(a), the sharp diffraction peaks attest the crystallinity of the alloy ribbons while the absence of any oxide impurities is also confirmed from the diffraction pattern. The characteristic diffraction peaks of the $\mathrm{Sn}_{80} \mathrm{Sb}_{20}$ ribbon correspond to rhombohedral $\beta$-SnSb phase (JCPDS card no. 33-0118) and tetragonal $\alpha$-Sn phase (JCPDS card no. 04-0673), respectively. Meanwhile, the XRD patterns of $\mathrm{Sn}_{20} \mathrm{Sb}_{80}$ ribbon are identified as rhombohedral $\beta$-SnSb phase and rhombohedral $\alpha$-Sb phase (JCPDS card no. 35-0732), while a single $\beta$-SnSb phase is recognized for the $\mathrm{Sn}_{50} \mathrm{Sb}_{50}$ one. Next, we examined the surface topography and composition of the alloy ribbons. Although the dimension of SnSb ribbons with different molar ratio are not the same, as the digital images show, all the as-obtained ribbons displayed the smooth surface without aggregated particles or voids in SEM (Figure 1(b)). That should be thanks to such high cooling speed of the melt-spinning technique effectively stop further grain growth that usually induces segregation. The quantitative elemental analysis of EDS reveals that the compositions of as-obtained alloy ribbons are well in agreement with the nominal compositions.

\subsection{Electrochemical Performance of P-SnSb}

The electrochemical properties of P-SnSb were tested in Li-ion battery by taking
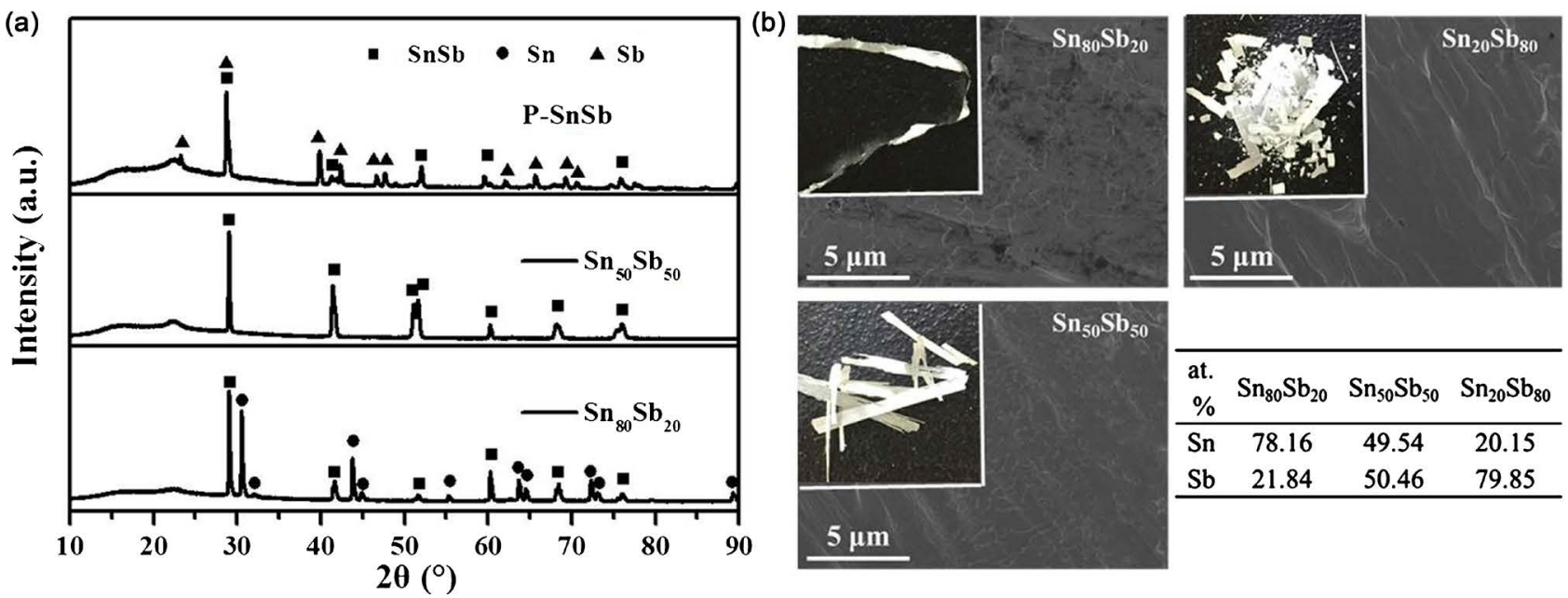

\begin{tabular}{rccc}
\hline $\begin{array}{r}\text { at. } \\
\%\end{array}$ & $\mathrm{Sn}_{80} \mathrm{Sb}_{20}$ & $\mathrm{Sn}_{50} \mathrm{Sb}_{50}$ & $\mathrm{Sn}_{20} \mathrm{Sb}_{80}$ \\
\hline $\mathrm{Sn}$ & 78.16 & 49.54 & 20.15 \\
$\mathrm{Sb}$ & 21.84 & 50.46 & 79.85 \\
\hline
\end{tabular}

Figure 1. (a) The XRD patterns of the alloy ribbons with different composition; (b) The SEM images and actual compositions of the alloy ribbons. The in sets are corresponding digital images of ribbons. 
galvanostatic discharge/charge tests at a current density of $100 \mathrm{~mA} \mathrm{~g}^{-1}$ between 0.1 and 1.5 V. According to the typical charge-discharge profiles (Figure 2(a)), the $\mathrm{P}-\mathrm{Sn}_{80} \mathrm{Sb}_{20}$ delivered a lithium capacity of $\sim 780 \mathrm{mAh} \mathrm{g}^{-1}$ for the first cycle with initial coulombic efficiency of $99 \%$ while $\mathrm{P}-\mathrm{Sn}_{50} \mathrm{Sb}_{50}$ and $\mathrm{P}-\mathrm{Sn}_{20} \mathrm{Sb}_{80}$ did $\sim 530$ $\mathrm{mAh} \mathrm{g}^{-1}$ and $\sim 40 \mathrm{mAh} \mathrm{g}^{-1}$ (Figure 2(b), Figure 2(c)) respectively. After 10 cycles, $\mathrm{P}-\mathrm{Sn}_{80} \mathrm{Sb}_{20}$ retained a capacity of $\sim 470 \mathrm{mAh} \mathrm{g}^{-1}$, which was much superior to the $\sim 150 \mathrm{mAh} \mathrm{g}^{-1}$ of $\mathrm{Sn}_{50} \mathrm{Sb}_{50}$. As to $\mathrm{P}-\mathrm{Sn}_{20} \mathrm{Sb}_{80}$, its initial coulombic efficiency was just $44.8 \%$ and the dramatic capacity degradation happened at the second cycle when the capacity jumped to $\sim 34 \mathrm{mAh} \mathrm{g}^{-1}$. In addition, lithiation/delithiation reaction of $\mathrm{P}-\mathrm{Sn}_{80} \mathrm{Sb}_{20}$ occurred between a narrow voltage range of $0.1-1.0 \mathrm{~V}$, delivering capacity evenly with a stepwise characteristic, while the other two did inferiorly. So, the $\mathrm{Sn}_{80} \mathrm{Sb}_{20}$ one was supposed deserving the further dealloying treatment.

\subsection{Microstructural and Phase Characterizations of NP-SnSb}

Based on electrochemical measurements, we selected $\mathrm{Sn}_{80} \mathrm{Sb}_{20}$ ribbon to exert chemical dealloying As shown in Figure 3(a), after 72 hours etching, the as-dealloyed NP-SnSb exhibits a three-dimensional bicontinuous nanoporus structure, with average pore size of $\sim 590 \mathrm{~nm}$. Figure $3(\mathrm{~b})$ shows the changes in XRD pattern after dealloying processe. The NP-SnSb and P-SnSb are both made of Sn pahse and SnSb pahse, but the peak intensity of Sn phase in NP-SnSb are
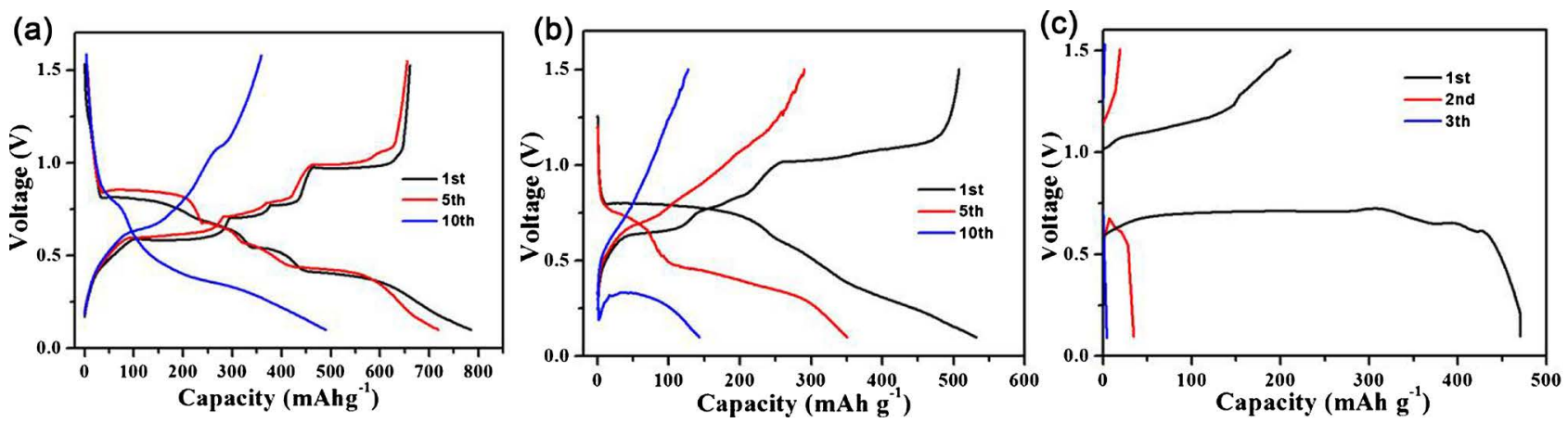

Figure 2. The typical charge-discharge profiles of pristine ribbons (a) $\mathrm{Sn}_{80} \mathrm{Sb}_{20}$; (b) $\mathrm{Sn}_{50} \mathrm{Sb}_{50}$; (c) $\mathrm{Sn}_{20} \mathrm{Sb}_{80}$ at current density of 100 $\mathrm{mA} \mathrm{g}^{-1}$.
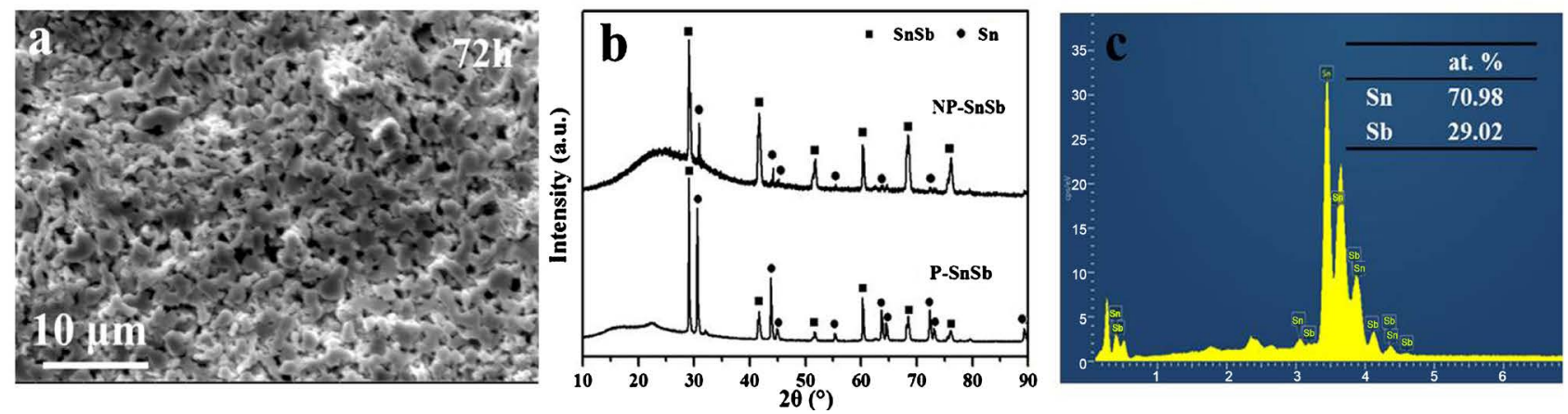

Figure 3. (a) The SEM images of the as-obtained NP-SnSb ribbon; (b) The XRD pattern of the ribbons before and after dealloying; (c) The EDS results of the NP-SnSb ribbon. 
obviously decreased. It is consistent with the composition results of $\mathrm{NP}-\mathrm{SnSb}$ (Figure $3(\mathrm{c})$ ) that the molar ratio of $\mathrm{Sn}$ to $\mathrm{Sb}$ is $\sim 70: 30$, which reduced from the initial $\sim 80: 20$, suggesting Sn was selectively dissolved because of its higher electrochemically activity.

Figure 4 shows the morphology evolution of SnSb ribbon during the dealloying process. It can be seen that river pattern cracks appeared as the etching time reached 24 hours (Figure $4(\mathrm{a})$ ), then bunch of pinpoint holes generated between cracks after 48 hours (Figure 4(b)), and bigger holes showed up among the smaller ones when the total time was 60 hours (Figure 4(c)). It is certain that the morphology of alloy ribbon changed as the etching time increased and regulated pores does not form until the etching time was up to 72 hours.

\subsection{Electrochemical Performance of NP-SnSb}

Figure 5(a) shows comparison of cycling performance delivered by pristine ribbon, NP-SnSb and $48 \mathrm{~h} / 60 \mathrm{~h}$-etched counterparts at current density of 100 $\mathrm{mA} \mathrm{g}^{-1}$ between 0.1 and $2.5 \mathrm{~V}$. Obviously, as time goes by, the cycling performance of alloy ribbon are getting better. And the NP-SnSb anode has the best capacity and cyclic capability as it delivered a initial capacity of $\sim 800 \mathrm{mAh} \mathrm{g}^{-1}$ and retained $\sim 750 \mathrm{mAh}$ after 15 cycles, while the other three have been totally failed earlier. It is the bicontinuous structural feature endows the electrodes with high tolerance toward the volume expansion during discharge/charge process, thereby improving the cycle stability. Furthermore, although suffering from the loss of $\mathrm{Sn}$, the supposed capacity declining of NP-SnSb does happen yet. The reason should be the open porous structure and high surface area of NP-SnSb benefit the permeating of electrolyte into the electrodes, thus permitting more Li participating reaction and give a capacity compensation. On the other hand, compared to P-SnSb (Figure 5(b) inset), NP-SnSb can form a more stable solid electrolyte interphase (SEI), as electrochemical impedance spectroscopy (EIS) (Figure 5(b)) exhibits less increase in the charge transfer resistance, as derived from the diameter of the semicircle in the high-frequency region. Correspondently, the SEM images of cycled electrode show that the NP-SnSb ribbon after 10 cycles (Figure $5(\mathrm{c})$ ) is still of being regulated porous like, whereas the $\mathrm{P}-\mathrm{SnSb}$ ribbon has been cracked (Figure $5(\mathrm{~d})$ ). And consistently, although inferior to
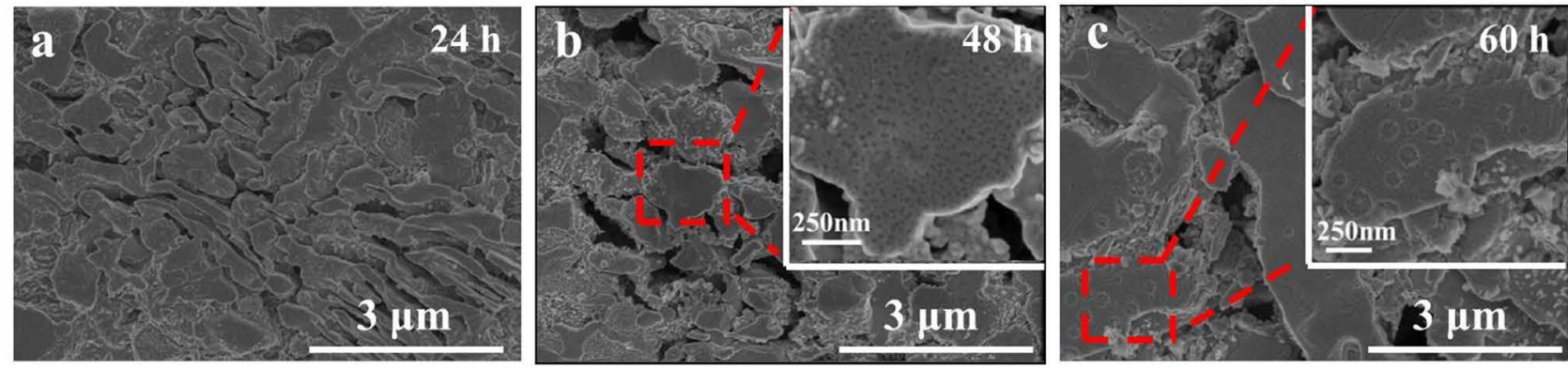

Figure 4. The SEM images showing morphology evolution of alloy ribbons experiencing dealloying time of (a) 24 h; (b) 48 h; (c) $60 \mathrm{~h}$. 

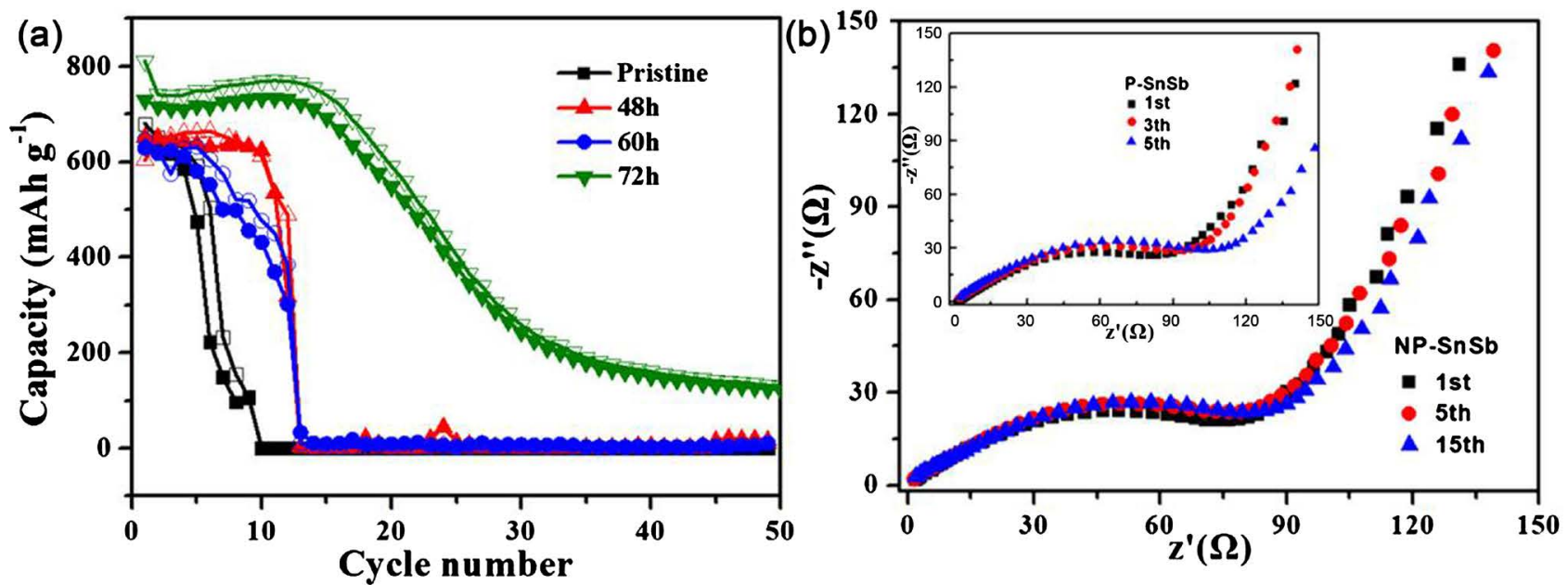

(c)

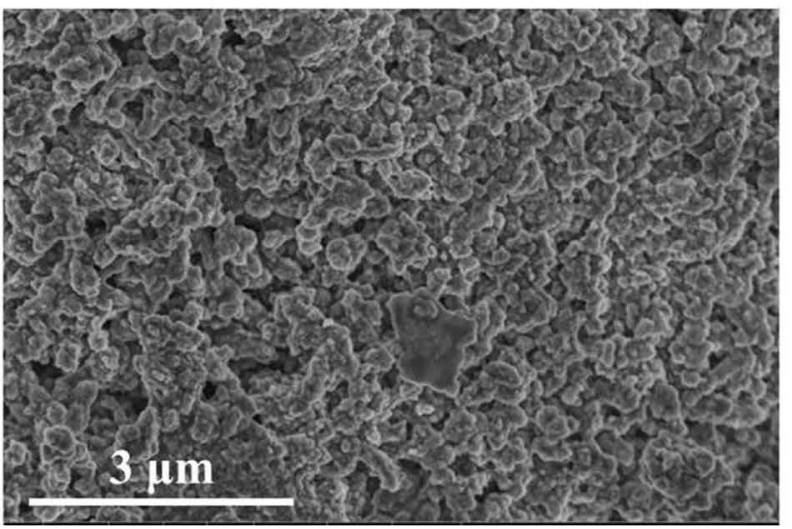

(d)

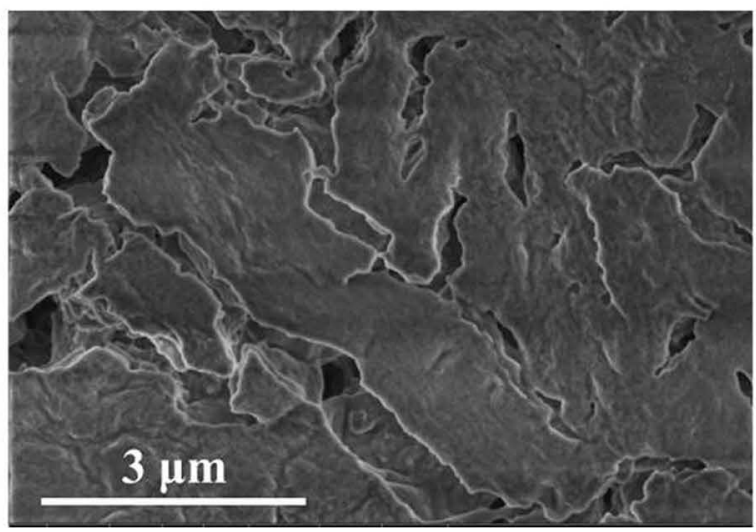

Figure 5. (a) The Cycling performance of different SnSb ribbon anodes; (b) The Nyquist plots of the impedance spectra of NP-SnSb and P-SnSb anode; (c) The SEM image of NP-SnSb anode after 10 cycles; (d) The SEM image of P-SnSb anode after 3 cycles.

the NP-SnSb, the performance of the $48 \mathrm{~h} / 60 \mathrm{~h}$ ribbons are still better than the pristine one, that should come from the surface pores also release the strain caused by lithiation and facilitate electrolyte invasion in some level.

Furthermore, the lithiation/delithiation kinetics of the NP-SnSb and P-SnSb were investigated by gauging the electrochemical response to increasing scan rates in $\mathrm{CV}$ test (Figure 6(a), Figure $6(\mathrm{c})$ ). $\mathrm{As} \mathrm{Li}_{\mathrm{x}} \mathrm{Sb}$ and $\mathrm{Li}_{\mathrm{x}} \mathrm{Sn}$ alloys formed successively [30] [31]:

$$
\begin{aligned}
3 \mathrm{Li}+\mathrm{SnSb} & \rightleftarrows \mathrm{Li}_{3} \mathrm{Sb}+\mathrm{Sn}(\sim 0.82 \mathrm{~V}) \\
4 \mathrm{Li}+\mathrm{Sn} & \rightleftarrows \mathrm{Li}_{4.4} \mathrm{Sn}(<0.66 \mathrm{~V})
\end{aligned}
$$

The oxidation/reduction peaks between $0.3-0.7 \mathrm{~V}$ and $0.6-0.8 \mathrm{~V}$ indicate the lithiation/delithiation of $\mathrm{Sn}$, as the couple of cathodic/anodic peaks appeared at $\sim 0.8$ and $\sim 1.0 \mathrm{~V}$ are related to the reaction between $\mathrm{Sb}$ and $\mathrm{Li}$. As the scan rates increase from 0.1 to $2 \mathrm{mV} \mathrm{s}^{-1}$, significant peak shifts occur and the corresponding peak currents are plotted based on the power law [32] [33]:

$$
\log i_{p}=b \log v+\log a
$$

where $i_{\mathrm{p}}$ is the peak current, $v$ is the scan rate, a and $\mathrm{b}$ are constants. 

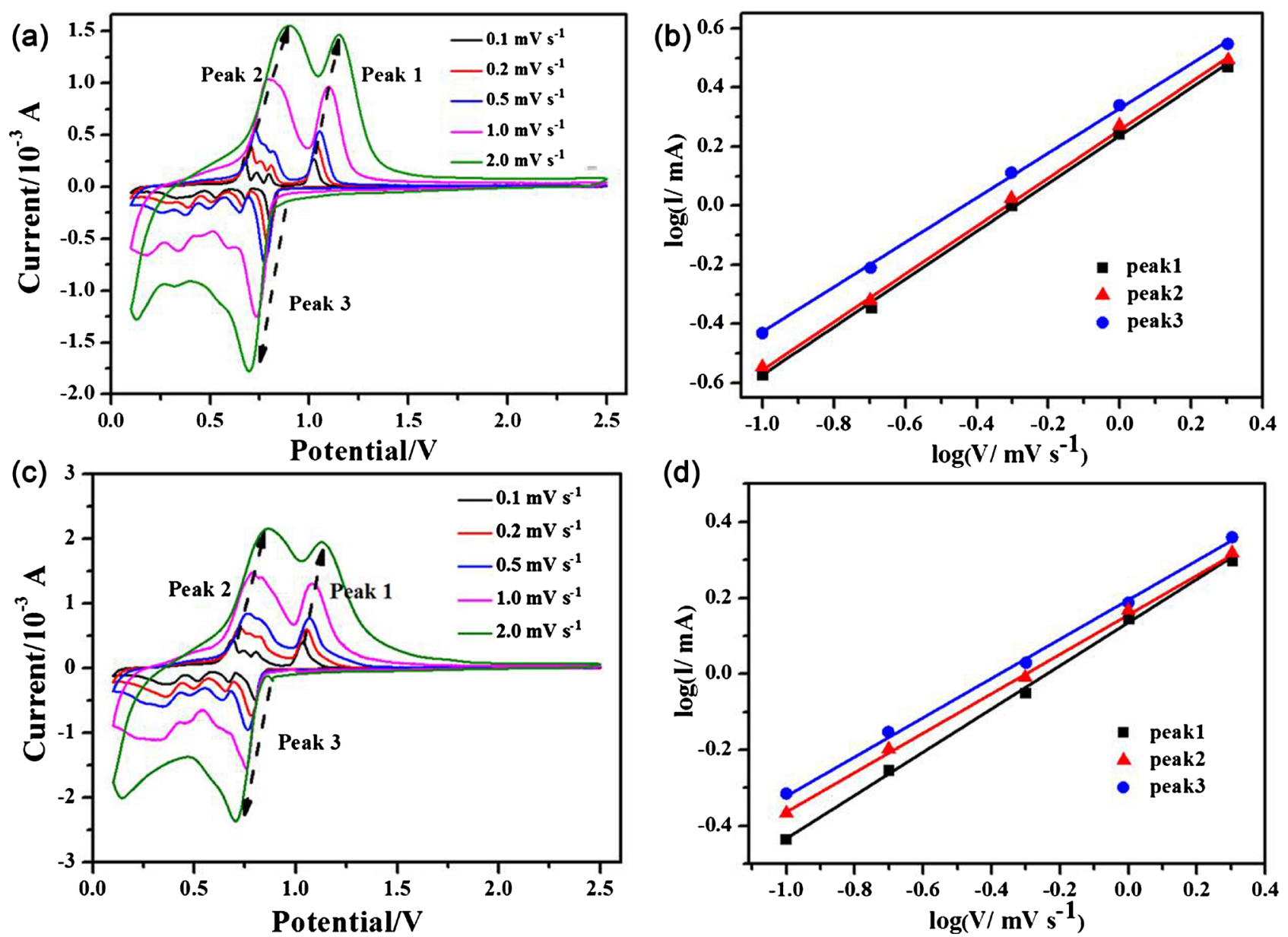

Figure 6. (a) and (b) The cyclic voltammogram and $\log (i)$ vs. $\log (v)$ relationship of NP-SnSb; (c) and (d) The Cyclic voltammogram and $\log (i)$ vs. $\log (v)$ relationship of P-SnSb.

Figure 6(b) shows the linear relationship between $\log (i)$ and $\log (v)$ for the peak currents of NP-SnSb. The "b" values deduced from the slope of the line are $0.80,0.81$ and 0.76 for peaks 1,2 , and 3, respectively, which obviously superior to $0.56,0.52$ and 0.51 of P-SnSb (Figure $6(\mathrm{~d})$ ). While b value close to 1.0 indicate kind of pseudocapacitive behavior and 0.5 shows a solid-state diffusion behavior, NP-SnSb obviously can get its superior kinetic capability from pseudocapacitive contributions. And the pseudocapacity is supposed come from that the high surface network of porous structure ensures a significant portion of Li-ions stored in the near surface region of the electrodes.

\section{Conclusion}

In summary, NP-SnSb electrodes were synthesized using a simple, low-cost and scalable melt-spinning/chemical-etching process. During serve as an anode in LIBs, the NP-SnSb electrode exhibited superior cycling capability and kinetics property to $\mathrm{P}-\mathrm{SnSb}$. That are attributed to the porous structure of the NP-SnSb help enhance the volume expansion tolerance and charge transport simultaneously. Additionally, the usage of ribbon electrode provide an new strategy for 
development of advanced anode materials, and further studies could be done to optimize the porous structure of electrode, eventually to assure stable capacity delivery in practical applications.

\section{Fund}

This work is financially supported by the National Natural Science Foundation of China (51671077), Natural Science Foundation of Hebei Province, China (E2016202212) and Key Project of Science \& Technology Research of Higher Education Institutions of Hebei Province, China (ZD2018059).

\section{Conflicts of Interest}

The authors declare no conflicts of interest regarding the publication of this paper.

\section{References}

[1] Zuo, X., Zhu, J., Müller-Buschbaum, P. and Cheng, Y.J. (2017) Silicon Based Lithium-Ion Battery Anodes: A Chronicle Perspective Review. Nano Energy, 31, 113-143. https://doi.org/10.1016/j.nanoen.2016.11.013

[2] Su, X., Wu, Q., Li, J., Xiao, X., Lott, A., Lu, W., Sheldon, B.W. and Wu, J. (2014) Silicon-Based Nanomaterials for Lithium-Ion Batteries: A Review. Advanced Energy Materials, 4, 1300882. https://doi.org/10.1002/aenm.201300882

[3] McDowell, M.T., Lee, S.W., Nix, W.D. and Cui, Y. (2013) Understanding the Lithiation of Silicon and Other Alloying Anodes for Lithium-Ion Batteries. Advanced Materials, 25, 4966-4985. https://doi.org/10.1002/adma.201301795

[4] Li, Z., Ding, J. and Mitlin, D. (2015) Tin and Tin Compounds for Sodium Ion Battery Anodes: Phase Transformations and Performance. Accounts of Chemical Research, 48, 1657-1665. https://doi.org/10.1021/acs.accounts.5b00114

[5] He, J., Wei, Y., Zhai, T. and Li, H. (2018) Antimony-Based Materials as Promising Anodes for Rechargeable Lithium-Ion and Sodiumion Batteries. Materials Chemistry Frontiers, 2, 437. https://doi.org/10.1039/C7QM00480J

[6] Luo, W., Gaumet, J.J. and Mai, L.Q. (2017) Antimony-Based Intermetallic Compounds for Lithium-Ion and Sodium-Ion Batteries: Synthesis, Construction and Application. Rare Metals, 36, 321-338. https://doi.org/10.1007/s12598-017-0899-4

[7] Shimoi, N., Komatsu, M., Tanaka, Y. and Tohji, K. (2018) Mechanochemically Metamorphosed Composites of Homogeneous Nanoscale Silicon and Silicate Oxides with Lithium and Metal Compounds. Materials Sciences and Applications, 18, 111-125.

[8] Balogun, M.S., Luo, Y., Qiu, W., Liu, P. and Tong, Y. (2016) A Review of Carbon Materials and Their Composites with Alloy Metals for Sodium Ion Battery Anodes. Carbon, 98, 162-178. https://doi.org/10.1016/j.carbon.2015.09.091

[9] Sengupta, S., Mitra, A., Dahiya, P.P., Kumar, A., Mallik, M., Das, K., Majumder, S.B. and Das, S. (2017) Investigation on Lithium Conversion Behavior and Degradation Mechanisms in Tin Based Ternary Component Alloy Anodes for Lithium Ion Batteries. Journal of Alloys and Compounds, 721, 236-248. https://doi.org/10.1016/j.jallcom.2017.06.005

[10] Tang, Y., Zhang, Y., Li, W., Ma, B. and Chen, X. (2015) Rational Material Design for Ultrafast Rechargeable Lithium-Ion Batteries. Chemical Society Reviews, 44, 
5926-5940. https://doi.org/10.1039/C4CS00442F

[11] He, W.D., Ye, L.H., Wen, K.C., Liang, Y.C., Lv, W.Q., Zhu, G.L. and Zhang, K.H.L. (2016) Materials Research Advances towards High-Capacity Battery/Fuel Cell Devices. Journal of Electronic Science and Technology, 14, 12-20.

[12] Yang, J., Wachtler, M., Winters, M. and Besenhard, J.O. (1999) Sub-Microcrystalline $\mathrm{Sn}$ and $\mathrm{Sn}-\mathrm{SnSb}$ Powders as Lithium Storage Materials for Lithium-Ionb Atteries. Electrochemical and Solid-State Letters, 2, 161-163. https://doi.org/10.1149/1.1390769

[13] Wang, Z.J., Toyohiko, K. and Ma, C.L. (2013) Comparative TEM Investigation on the Precipitation Behaviors in Cu-15 wt\% Sn Alloy. Rare Metals, 32, 139-143. https://doi.org/10.1007/s12598-013-0033-1

[14] Todd, A., Mar, R. and Dahn, J.R. (2007) Tin-Transition Metal-Carbon Systems for Lithium-Ion Battery Negative Electrodes. Journal of the Electrochemical Society, 154, A597-A604. https://doi.org/10.1149/1.2724741

[15] Ma, L., Yan, P., Wu, S., Zhu, G. and Shen, Y. (2017) Engineering Tin Phosphides@ Carbon Yolk-Shell Nanocube Structures as a Highly Stable Anode Material for Sodium-Ion Batteries. Journal of Materials Chemistry A, 5, 16994-17000. https://doi.org/10.1039/C7TA04900E

[16] Qin, J., Zhao, N., Shi, C., Liu, E., He, F., Ma, L., Li, Q., Li, J. and He, C. (2017) Sandwiched $\mathrm{CSnO}_{2} \mathrm{C}$ Hollow Nanostructures as an Ultralong-Lifespan High-Rate Anode Material for Lithium-Ion and Sodium-Ion Batteries. Journal of Materials Chemistry A, 5, 10946-10956. https://doi.org/10.1039/C7TA01936

[17] Kim, J.H. and Kang, Y.C. (2017) Synthesis of Uniquely Structured Yolk-Shell Metal Oxide Microspheres Filled with Nitrogen-Doped Graphitic Carbon with Excellent Li-Ion Storage Performance. Small, 13, Article ID: 1701585. https://doi.org/10.1002/smll.201701585

[18] Mao, O., Turner, R.L., Courtney, I.A., Fredericksen, B.D., Buckett, M.I., Krause, L.J. and Dahn, J.R. (1999) Active/Inactive Nanocomposites as Anodes for Li-Ion Batteries. Electrochemical and Solid-State Letters, 2, 3-5. https://doi.org/10.1149/1.1390715

[19] Li, S., Niu, J., Zhao, Y.C., So, K.P., Wang, C., Wang, C.A. and Li, J. (2015) High-Rate Aluminium Yolk-Shell Nanoparticle Anode for Li-Ion Battery with Long Cycle Life and Ultrahigh Capacity. Nature Communications, 6, Article No. 7872. https://doi.org/10.1038/ncomms8872

[20] Li, S., Wang, Z., Liu, J., Yang, L., Guo, Y., Cheng, L., Lei, M. and Wang, W. (2016) Yolk-Shell SnC Eggette-Like Nanostructure: Application in Lithium-Ion and Sodium-Ion Batteries. ACS Applied Materials \& Interfaces, 8, 19438-19445. https://doi.org/10.1021/acsami.6b04736

[21] Xie, W., He, J., Kang, H.J., Tang, X., Zhu, S., Laver, M., Wang, S., Copley, J.R.D., Brown, C.M., Zhang, Q. and Tritt, T.M. (2010) Identifying the Specific Nanostructures Responsible for the High Thermoelectric Performance of $(\mathrm{Bi}, \mathrm{Sb})_{2} \mathrm{Te}_{3} \mathrm{Nano}-$ composites. Nano Letters, 10, 3283-3289. https://doi.org/10.1021/nl100804a

[22] Manaf, A., Buckley, R.A., Davies, H.A. and Leonowicz, M. (1991) Enhanced Magnetic Properties in Rapidly Solidified Nd-Fe-B Based Alloys. Journal of Magnetism and Magnetic Materials, 101, 360-362. https://doi.org/10.1016/0304-8853(91)90779-A

[23] Bruce, P.G., Scrosati, B. and Tarascon, J.M. (2008) Nanomaterials for Rechargeable Lithium Batteries. Angewandte Chemie International Edition, 47, 2930-2946. https://doi.org/10.1002/anie.200702505 
[24] Schoonman, J. (2000) Nanostructured Materials in Solid State Ionics. Solid State Ionics, 135, 5-19. https://doi.org/10.1016/S0167-2738(00)00324-6

[25] Van der Ven, A., Marianetti, C., Morgan, D. and Ceder, G. (2000) Phase Transformations and Volume Changes in Spinel $\mathrm{Li}_{\mathrm{x}} \mathrm{Mn}_{2} \mathrm{O}_{4}$. Solid State Ionics, 135, 21-23. https://doi.org/10.1016/S0167-2738(00)00326-X

[26] Yu, Y., Gu, L., Lang, X., Zhu, C., Fujita, T. and Chen, M. (2011) Li Storage in 3D Nanoporous Au-Supported Nanocrystalline Tin. Advanced Materials, 23, 2443 2447. https://doi.org/10.1002/adma.201004331

[27] Etacheri, V., Seisenbaeva, G.A., Daniel, J., Nedelec, G.J.M., Kessler, V.G. and Pol, V.G. (2015) Ordered Network of Interconnected $\mathrm{SnO}_{2}$ Nanoparticles for Excellent Lithium-Ion Storage. Advanced Energy Materials, 5, 1614-6840. https://doi.org/10.1002/aenm.201401289

[28] Jiao, Y., Han, D., Ding, Y., Zhang, X., Guo, G., Hu, J., Yang, D. and Dong, A. (2015) Fabrication of Three-Dimensionally Interconnected Nanoparticle Superlattices and Their Lithium-Ion Storage Properties. Nature Communications, 6, Article No. 6420. https://doi.org/10.1038/ncomms7420

[29] Li, H., Wang, Q., Shi, L., Chen, L. and Huang, X. (2002) Nanosized SnSb Alloy Pinning on Hard Non-Graphitic Carbon Spherules as Anode Materials for a Li Ion Battery. Chemistry of Materials, 14, 103-108. https://doi.org/10.1021/cm010195p

[30] Park, M.S., Needham, S.A., Wang, G.X., Kang, Y.M., Park, J.S., Dou, S.X. and Liu, H.K. (2007) Nanostructured SnSb/Carbon Nanotube Composites Synthesized by Reductive Precipitation for Lithium-Ion Batteries. Chemistry of Materials, 19, 2406 2410. https://doi.org/10.1021/cm0701761

[31] Tirado, J.L., Jumas, J.C. and Olivier-Fourcade, J. (2002) X-Ray Diffraction, 7Li MAS NMR Spectroscopy, and 119Sn Mössbauer Spectroscopy Study of SnSb-Based Electrode Materials. Chemistry of Materials, 14, 2962-2968. https://doi.org/10.1021/cm0112800

[32] Augustyn, V., Come, J., Lowe, M.A., Kim, J.W., Taberna, P.L., Tolbert, S.H., Abruña, H.D., Simon, P. and Dunn, B. (2013) High-Rate Electrochemical Energy Storage through $\mathrm{Li}^{+}$Intercalation Pseudocapacitance. Nature Materials, 12, 518-522.

[33] Wang, J., Polleux, J., Lim, J. and Dunn, B. (2007) Pseudocapacitive Contributions to Electrochemical Energy Storage in $\mathrm{TiO}_{2}$ (Anatase) Nanoparticles. The Journal of Physical Chemistry C, 111, 14925-14931. https://doi.org/10.1021/jp074464w 